\title{
Mechanical properties of lightweight foam concrete filler for roadbed of high-speed railway
}

\author{
De-Gou Cai ${ }^{1,2} \cdot$ Shao-Wei Wei ${ }^{1,2,3} \cdot$ Yang-Sheng Ye ${ }^{2,4} \cdot$ Qian-Li Zhang ${ }^{1,2} \cdot$ Zhong-Guo Li $^{1,2} \cdot \mathrm{Si} \mathrm{Li}^{3}$
}

Received: 24 March 2020 / Accepted: 13 April 2021 / Published online: 17 May 2021

(C) The Author(s) 2021

\begin{abstract}
A high-speed railway has high requirements for line smoothness, and uneven settlement control is the primary factor considered in the design and operation of the subgrade. The emergence of lightweight subgrade structures meets the needs of the development of the high-speed railway. As a kind of filling material with good performance, lightweight foam concrete can effectively reduce the load and excessive settlement of subgrade and effectively reduce the cost of foundation treatment. This paper studied the dynamic characteristics of lightweight foam concrete with different wet densities and water-bearing states under train loading. The effects of wet density and fly ash content on the compressibility, impermeability, and frost resistance of lightweight foam concrete were analyzed in detail. The results show that the lightweight foam concrete still has high residual strength after compression, which is about $60 \%$ of its peak strength. Under different mix ratios, the critical dynamic stress of the lightweight foam concrete is generally $0.2-0.3$ times the unconfined compressive strength, and the dynamic elastic modulus increases with the increase of wet density and cyclic stress amplitude. With the fly ash content increasing, the volume water absorption of lightweight foam concrete decreases first and then increases, and the critical value of fly ash content is $40 \%$. The frost resistance of lightweight foam concrete gradually increases with the increase of wet density, and the dynamic elastic modulus of the sample with $279 \mathrm{~kg} \cdot \mathrm{m}^{-3}$ density lost $41.1 \%$ after 20 freeze-thaw cycles. When the content of fly ash is $20 \%$, the frost resistance of lightweight foam concrete is equivalent to that of pure cement.
\end{abstract}

Keywords Lightweight foam concrete $\cdot$ Wet density $\cdot$ Dynamic properties $\cdot$ Compressive strength $\cdot$ Impermeability $\cdot$ Frost resistance

\section{Introduction}

Due to the fast speed of high-speed railway and high requirements for line smoothness, the control of uneven settlement is

Responsible Editor: Zeynal Abiddin Erguler

Shao-Wei Wei

18888850458@163.com

1 Railway Engineering Research Institute, China Academy of Railway Sciences Corporation Limited, 100081 Beijing, China

2 State Key Laboratory for Track Technology of High-Speed Railway, China Academy of Railway Sciences Corporation Limited, Beijing 100081, China

3 Beijing Tieke Special Engineering Technology Corporation Limited, Beijing 100081, China

4 China Academy of Railway Sciences Corporation Limited, Beijing 100081, China the primary factor to be considered in roadbed design. China's geological conditions are very complicated; the traditional foundation treatment methods are mostly used in the existing settlement control, which in soft soil areas and transition sections is not ideal. Therefore, it is particularly urgent to research and develop new and more adaptable roadbed structures and filling materials.

Lightweight foam concrete is a kind of lightweight cementbased material prepared by introducing air bubbles into cement paste or mortar by appropriate foaming means (Ramamurthy et al. 2009; Liu et al. 2016; Hu et al. 2016). This material has the advantages of lightweight, high strength, good fluidity, stable performance, strong uprightness, and low environmental impact and has been widely used in geotechnical engineering (Hilal et al. 2015; Amran et al. 2015; Kuzielov et al. 2016). In 1986, lightweight foam concrete was first applied as road filling in Japanese road construction so as to reduce the load and effectively treat road landslides (Toshiyasu et al. 2000). Satoh et al. (2001) analyzed the 
feasibility of lightweight foam concrete as port filler and considered that the density of lightweight foam concrete as port filler was the same as that of 28 days after 1 year, but the strength increased by $40 \%$. Otain et al. (2002) scanned the lightweight foam concrete samples of Kumamoto Airport by CT technology and analyzed the bubble distribution and compressive strength of the lightweight foam concrete during pouring under different mix ratios. In the previous researches, the wet density of lightweight foam concrete is mainly concentrated in the range of 520 to $670 \mathrm{~kg} \cdot \mathrm{m}^{-3}$, which is narrow. It is necessary to study the mechanical properties of lightweight foam concrete with a wider range of wet densities.

At present, the researches on lightweight foam concrete are mainly focused on the mix ratio, pore structure, mechanical properties, thermal insulation, and durability and have achieved considerable results. Kearsley and Wainwright (2002) studied the effects of pore structure, fly ash, and other factors on the strength of lightweight foam concrete. Cong and Chen (2015) incorporated soil particles and silica fume into lightweight foam concrete and investigated the mechanical properties and water absorption of the specimens. Hengst and Tressler (1983) thought that for lightweight foam concrete with a given density, the main parameter determining its strength was the defect size related to the pore size. Kearsley and Wainwright $(2001,2002)$ studied the effects of fly ash content and porosity on the strength of lightweight foam concrete and established the mathematical models of porosity, age, and compressive strength. Based on the artificial intelligence technology, Ashrafian et al. (2020) proposed an adaptive multivariate adaptive regression splines optimized using water cycle algorithm model for predicting the compressive strength of lightweight foam concrete. Gopalakrishnan et al. (2019) pointed out that the optimum content of fly ash in lightweight foam concrete is $20 \sim 25 \%$, which could improve the short-term compressive strength of concrete. When the content of fly ash exceeds $30 \%$, it will reduce its workability and affect the hardening performance. Falliano et al. (2019) found that the fracture behavior of lightweight foam concrete cured in air and water was different through FESEM images, and the compressive strength of curing in water to air increased by $10 \%$.

Lightweight foam concrete has large water absorption, which is twice as high as that of ordinary concrete with the same water binder. Improving the waterproof performance of foam concrete can significantly improve corrosion resistance and durability (Amran et al. 2015). At the same time, there is a strong correlation between the permeability and mechanical properties of lightweight foam concrete. Kearsley and Wainwright (2001) found that increasing the fly ash-cement ratio can significantly improve the permeability of concrete. Wang et al. (2019) also pointed out that a small amount of rubber powder can improve the waterproof performance of lightweight foam concrete. The review of Amran et al.
(2015) shows that the dry shrinkage decreases with the increase of aggregate and water content of lightweight foam concrete. At a higher water content, lightweight foam concrete will have larger shrinkage deformation (Jones and McCarthy 2005). The durability of lightweight foam concrete is also affected by repeated soaking and evaporation of watersoluble cementitious materials. Due to the short service time of lightweight foam concrete, there are few researches on its frost resistance. It is pointed out that the frost resistance of lightweight foam concrete is related to temperature. When the temperature rises and decreases relatively quickly, the frost resistance of lightweight foam concrete is poor (Tan et al. 2013). Jerman et al. (2013) found that the frost resistance index of strength and mass loss of aerated concrete is related to the water condition. After 50 freeze-thaw cycles, there is no strength loss and quality loss of aerated concrete in a dry state.

In this paper, the long-term dynamic characteristics of lightweight foam concrete with different densities and water-bearing states under cyclic loading were studied through a series of dynamic triaxial tests. The effects of wet density and fly ash content on the compressibility, impermeability, and frost resistance of lightweight foam concrete were analyzed in detail. The research results provide a theoretical reference for the application of lightweight foam concrete in the design and construction of ballastless track subgrades of high-speed railway.

\section{Experimental procedure}

\section{Sample preparation}

An A01 foaming agent was adopted in the preparation of samples. The foaming agent and water were diluted according to the optimum dilution ratio, put into the liquid storage tank, and then pressurized to $0.5 \mathrm{MPa}$ by an air compressor. Finally, the air valve and the liquid valve were opened so that the foaming liquid and air could be mixed in the foaming gun to obtain the foam.

When preparing the lightweight foam concrete sample, take the cement and water according to the water-cement ratio and stir evenly and then add the foam prepared by the foaming device and fully stir. The PVC pipe mold sealed at the bottom was taken for the lightweight foam concrete pouring. Each sample was a cylinder, with a size of $50 \mathrm{~mm}$ in diameter and $100 \mathrm{~mm}$ in height. After the pouring was completed, the samples were cured in the natural environment for 28 days and then removed in the mold. The sample of lightweight foam concrete is shown in Fig. 1.

\section{Selection of test parameters}

According to the on-site driving test results, the dynamic stress time-history response curve of the ballastless subgrade 


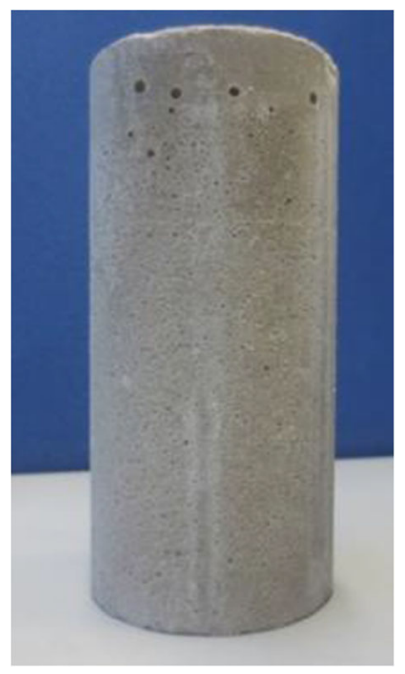

Fig. 1 Lightweight foam concrete sample

was obtained. It was found that the variation of the subgrade dynamic stress with time is close to the sine wave curve, and the frequency response range of the subgrade subjected to the axle action is between 3.9 and $15.5 \mathrm{~Hz}$. As far as the long-term dynamic stability of the roadbed is concerned, low-frequency load plays a controlling role in general, so the loading frequency of this test was set to $5 \mathrm{~Hz}$.

Considering the application of lightweight foam concrete material to the filler in the transition section and its upright, the confining pressure was taken as $30 \mathrm{kPa}$. Due to the different drainage conditions of the foundation bed, the lightweight foam concrete at different depths has different water-bearing states, so samples of lightweight foam concrete in natural drying and water saturation were selected for the dynamic triaxial test. The loading times of the test were 50,000 times.

The uniaxial compression tests of the lightweight foam concrete were carried out by using WDW computer control electronic universal testing machine. The impermeability test of lightweight foam concrete refers to the test principle of the seepage height method of ordinary concrete. The permeability was evaluated by the time required for all infiltration of the specimen. The specimen was a round table with a size of $175 \mathrm{~mm}$ in upper diameter, $185 \mathrm{~mm}$ in lower diameter, and $150 \mathrm{~mm}$ in height. The wet density was set to $400,500,600$, $700,800,900$, and $1000 \mathrm{~kg} \cdot \mathrm{m}^{-3}$. The water-cement ratios were $0.4,0.5,0.6$, and 0.7 .

\section{Analysis of dynamic properties}

\section{Critical dynamic stress}

Critical dynamic stress refers to the ability of materials to resist dynamic failure, which is usually expressed as the amplitude of dynamic stress required to reach a certain failure standard under a certain number of load cycles. Figure 2 shows the loading curves of lightweight foam concrete with different mix ratios under different dynamic stress amplitudes. It can be seen that the cumulative deformation is large at the beginning of 2000 cyclic loads. There are some fragile pores and defects on the surface of foamed lightweight concrete samples. These pores and defects are compacted at first, and a large cumulative deformation occurs when the number of actions is small. When the cyclic stress is less than or equal to the critical dynamic stress, the cumulative settlement is basically unchanged after a certain number of cyclic loading. When the cyclic stress is greater than the critical dynamic stress, the cumulative deformation continues to increase, which shows a linear increasing phenomenon until sudden failure. And the cumulative deformation increases with the increase of the dynamic stress amplitude.

Based on the analysis of the positive and negative relationships of the slope between the loading amplitude cumulative deformation, the critical dynamic stress of lightweight foam concrete under different mix ratios was obtained, as shown in Table 1. Under different mix ratios, the critical dynamic stress of lightweight foam concrete is generally $0.2 \sim 0.3$ times the unconfined compressive strength, which is slightly lower than that of geotechnical materials $(1 / 3 \sim 1 / 2)$.

When the density is low, the ratio of critical dynamic stress to the compressive strength of lightweight foam concrete in a $100 \%$ water-bearing state is lower than that in a natural dry state. The pore content of the sample with lower density is higher, which is easy to cause the phenomenon of "through hole." When the load acts on the top surface of the sample, the aqueous solution overflows from around, and the solid skeleton still plays the role of the strength of the sample. The high-

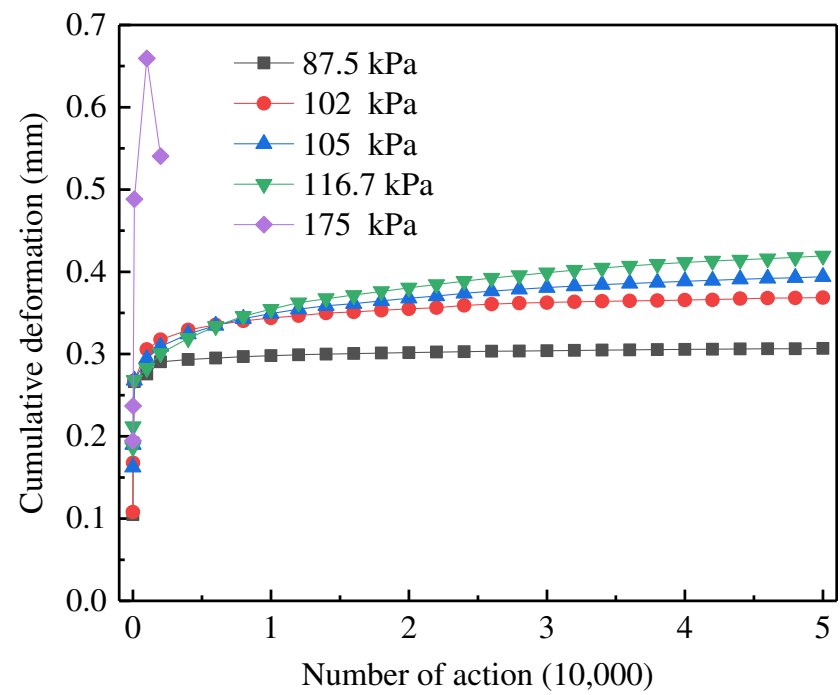

Fig. 2 Variations of the cumulative deformation with action times for lightweight foam concrete 
Table 1 Critical dynamic stress of lightweight foam concrete with different mix ratios

\begin{tabular}{lllll}
\hline $\begin{array}{l}\text { Density } \\
\left(\mathrm{kg} / \mathrm{m}^{3}\right)\end{array}$ & Water content & $\begin{array}{l}\text { Compressive } \\
\text { strength }(\mathrm{MPa})\end{array}$ & $\begin{array}{l}\text { Critical } \\
\text { dynamic } \\
\text { stress (MPa) }\end{array}$ & $\begin{array}{l}\text { Critical dynamic } \\
\text { stress/compressive } \\
\text { strength }\end{array}$ \\
\hline 500 & Natural drying & 0.35 & 0.1 & 0.29 \\
550 & 100\% water content & 0.28 & 0.06 & 0.21 \\
& Natural drying & 0.55 & 0.15 & 0.27 \\
600 & 100\% water content & 0.46 & 0.11 & 0.24 \\
650 & Natural drying & 0.82 & 0.21 & 0.26 \\
& 100\% water content & 0.73 & 0.21 & 0.29 \\
700 & Natural drying & 1.01 & 0.32 & 0.32 \\
& 100\% water content & 0.88 & 0.32 & 0.36 \\
& Natural drying & 1.18 & 0.35 & 0.30 \\
\hline
\end{tabular}

density sample can form a closed void, and the aqueous solution in the closed hole could not be discharged in time under the load. Due to the incompressibility of liquids, the sample can withstand greater stress, resulting in an increase in critical dynamic stress.

\section{Dynamic elastic modulus}

The variations of dynamic elastic modulus of lightweight foam concrete under different frequencies and loads are shown in Fig. 3. It can be seen that the dynamic elastic modulus of lightweight foam concrete increases with density and cyclic stress amplitude increasing. When the load amplitude is small, the dynamic elastic modulus shows a "fluctuation phenomenon." This is because the loading surface of the sample is not completely smooth, which may cause the top surface of the sample to bear all the stress loads locally, resulting in a lower dynamic elastic modulus. With the loading frequency increasing, when the lightweight foam concrete produces elastic deformation, the self-deformation is not completely recovered and the propagation velocity of stress wave in the multi-void foam material is slow, which causes the stress cancelation, and the dynamic elastic modulus tends to increase.

Water has a certain softening effect on the solid skeleton of lightweight foam concrete materials; the dynamic elastic modulus in the natural dry state is higher than that in the $100 \%$ water-bearing state under the same loading amplitude. At the same time, it can be found that when the density of lightweight foam concrete is between $550 \mathrm{~kg} \cdot$ and $650 \mathrm{~kg} \cdot \mathrm{m}^{-3}$, the dynamic elastic modulus is similar to that of graded macadam, which can be used as the mix ratio for laboratory tests.

\section{Hysteretic curve}

Figure 4 illustrates the hysteresis curve of lightweight foam concrete under repeated loading and unloading in a dynamic triaxial test. When the loading strength is less than the critical dynamic stress, the hysteretic curve is flat and thin, indicating that the viscosity of lightweight foam concrete is small and reflecting that its damping ratio and energy dissipation are small. The lightweight foam concrete mainly produces elastic deformation under the loading force, and the reciprocating deformation movement in an elastic state consumes almost no energy. When the loading strength is greater than the critical dynamic stress, the shape of the hysteretic curve tends to be wider and thicker. Under cyclic loading, in addition to the elastic deformation energy consumption, the lightweight foam

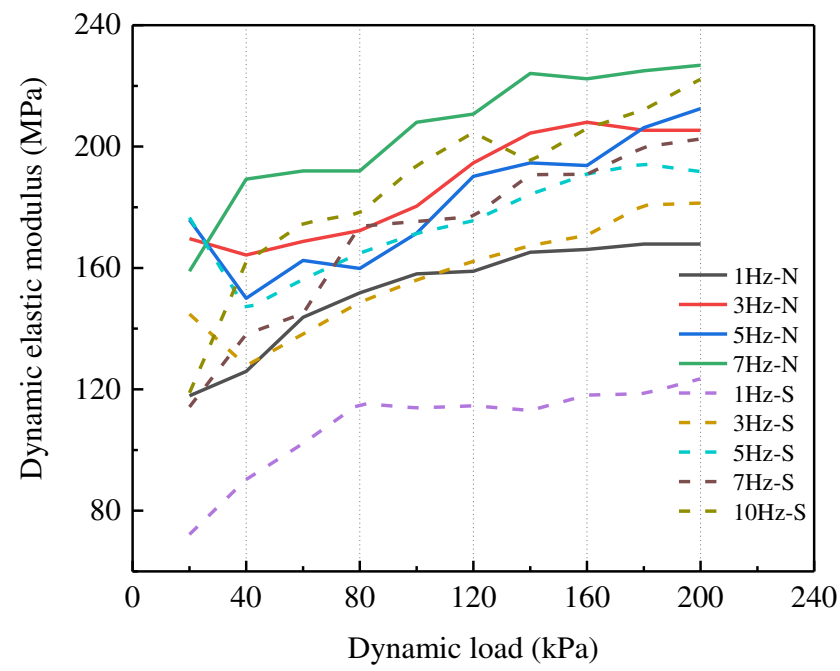

Fig. 3 Variation of dynamic elastic modulus of foam lightweight concrete under different frequencies $(\mathrm{N}$ is natural drying and $\mathrm{S}$ is $100 \%$ water content; $\rho=550 \mathrm{~kg} / \mathrm{m}^{3}$ as an example) 


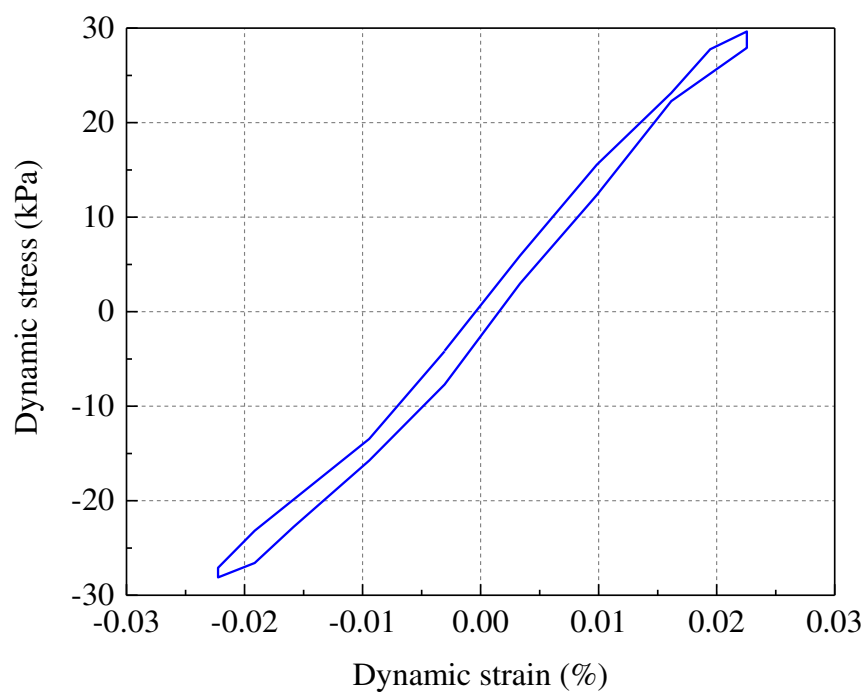

a

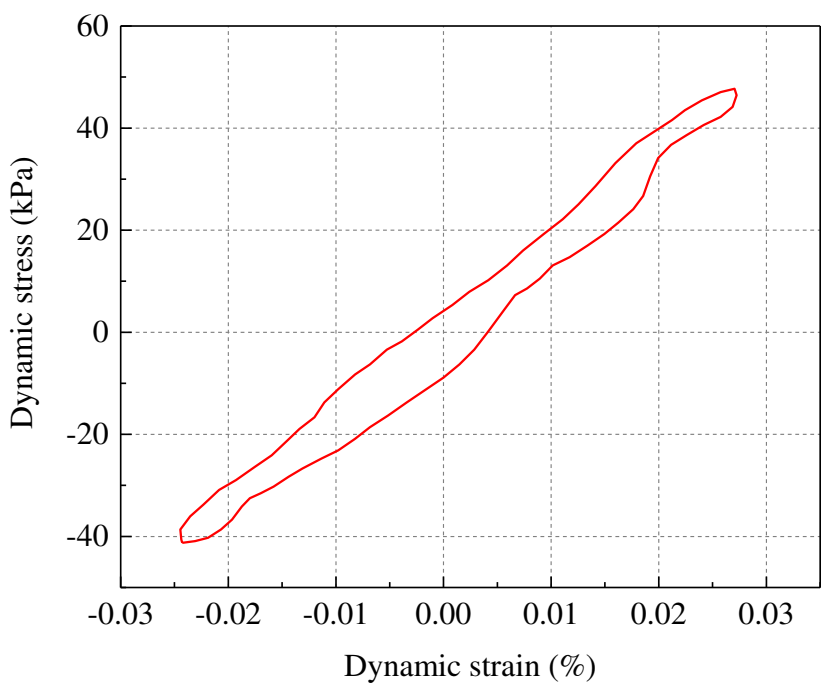

b

Fig. 4 Hysteresis curve of repeated loading and unloading in the dynamic triaxial test. a Less than critical dynamic stress. b Greater than critical dynamic stress

concrete sample produces cumulative plastic deformation, and the energy loss caused by solid particle friction increases gradually. Therefore, the hysteretic curve becomes wider and thicker and tends to be as smooth as the hysteretic curve of the viscoelastic body. When the lightweight foam concrete is used as the filling material of the offline structure, the actual engineering situation is not allowed to consume energy by the damage of the material itself.

\section{Analysis of durability}

\section{Compressive property}

The compressive stress-strain curves of lightweight foam concrete under different densities are shown in Fig. 5. It can be seen that the axial compression curve of the samples is basically divided into four stages. (1) Compaction stage: There are some fragile pores and defects in the lightweight foam concrete, which are compacted at first, and the stress increases slowly with strain. (2) Elastic stage: The stress increases linearly with the strain and changes greatly, and the external force is carried by the whole specimen. (3) Brittle stage: This stage is accompanied by the propagation of microcracks and the generation or collection of new cracks inside the specimen. The elastic modulus decreases compared with the elastic stage. (4) Yield stage: It could be divided into two failure cases: shock yield and point yield.

With the increase of wet density of lightweight foam concrete, the yield stage transitions from shock yield to point yield, and the amplitude of the point yield's sudden drop increases. In the compression process of lightweight foam concrete, the stress and strain are expressed as (a) elastic deformation within the range of strength, (b) plastic deformation after exceeding the strength, and (c) ductile failure. There is still a high residual strength after failure, which is about $60 \sim 70 \%$ of its peak strength.

\section{Impermeability test}

\section{Impermeability of lightweight foam concrete}

The impermeability test results of lightweight foam concrete under different wet densities and water-cement ratios are

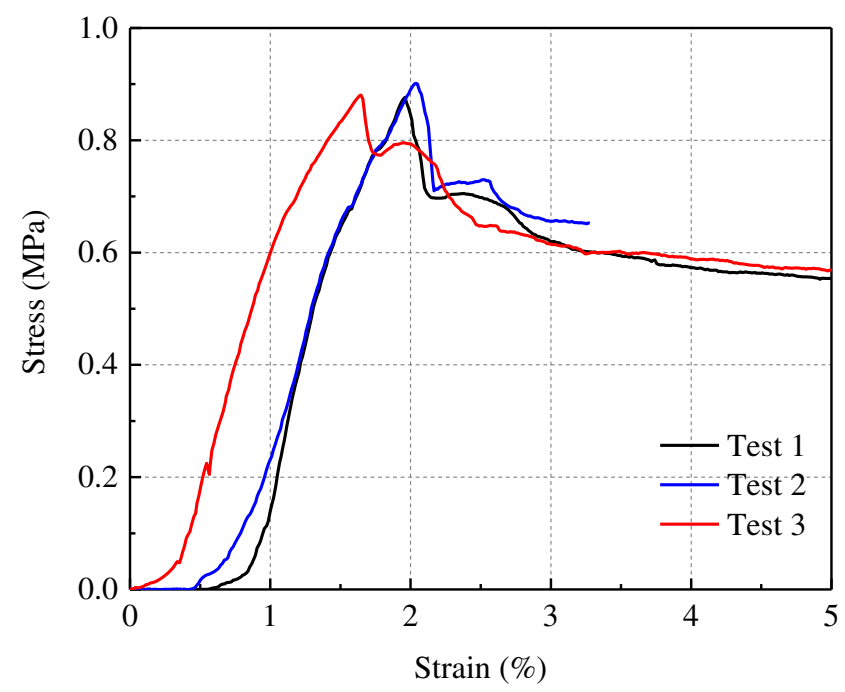

Fig. 5 Compressive stress-strain curves of foam lightweight concrete with different densities $\left(\rho=650 \mathrm{~kg} / \mathrm{m}^{3}\right.$ as an example) 
shown in Table 2. It can be seen that the infiltration time of lightweight foam concrete increases with the wet density increasing. When the wet density is less than $600 \mathrm{~kg} \cdot \mathrm{m}^{-3}$, the increment is small. While the infiltration time increases rapidly with the increase of wet density and basically increases linearly when the density is more than $600 \mathrm{~kg} \cdot \mathrm{m}^{-3}$. Lowdensity lightweight foam concrete has more foam added during the preparation process, the cement content is low, and the foam is easy to deform and burst. After setting and hardening, the porosity is high, and there are many macropores and connected pores. In addition, the water-cement ratio is larger than that of high density, and the excess water evaporates and leaves a bleeding channel in the process of setting and hardening. So the external water easily enters along the connected pores, and the corresponding impermeability is poor.

The infiltration time of lightweight foam concrete increases at first and then decreases with the increase of the water-cement ratio. When the water-cement ratio is relatively small, the fluidity of cement paste is not good, and a large number of cement particles agglomerate, which will cause the deformation and rupture of foam in the stirring process, resulting in the increase of internal defects and poor impermeability of lightweight foam concrete. With the increase of the water-cement ratio, the fluidity and uniformity of the slurry are improved, and the impermeability is improved. However, with the further increase of the water-cement ratio, the water layer surrounding the cement particles is thicker, and the amount of water not involved in the hydration reaction increases. The water easily infiltrates into the lightweight foam concrete, and its impermeability decreases.

\section{Analysis of volume water absorption}

With the increase of dry density, the water absorption of lightweight foam concrete decreases obviously, as shown in Fig. 6. The water absorption of low-density lightweight foam

Table 2 Impermeability test results of lightweight foam concrete

Number Wet density $\left(\mathrm{kg} / \mathrm{m}^{3}\right)$ Water cement ratio Infiltration time (h)

\begin{tabular}{llll}
\hline D4 & 400 & 0.75 & 0.51 \\
D5 & 500 & 0.70 & 0.72 \\
D6 & 600 & 0.65 & 1.28 \\
D7 & 700 & 0.60 & 2.62 \\
D8 & 800 & 0.55 & 4.57 \\
D9 & 900 & 0.53 & 6.13 \\
D10 & 1000 & 0.50 & 8.21 \\
W4 & 700 & 0.40 & 2.05 \\
W5 & 700 & 0.50 & 2.80 \\
W7 & 700 & 0.70 & 2.28 \\
\hline
\end{tabular}

concrete is very high, in which the water absorption of the sample with a dry density of $274 \mathrm{~kg} \cdot \mathrm{m}^{-3}$ reaches $86.5 \%$, while that of the sample with a dry density of $954 \mathrm{~kg} \cdot \mathrm{m}^{-3}$ reduces to $29.4 \%$. The variation of water absorption is more sensitive when the density of lightweight foam concrete is lower than $500 \cdot \mathrm{kg} \cdot \mathrm{m}^{-3}$. Figure 7 illustrates the scanning electron microscope images of the lightweight foam concrete sample. It can be seen that the pore size of the sample with a density of 500 $\mathrm{kg} \cdot \mathrm{m}^{-3}$ is large, and the pore diameter reaches $0.2 \sim 0.3 \mathrm{~mm}$. While the cell wall is very thin, about $0.03 \mathrm{~mm}$, which is only about one tenth of the pore diameter.

Mineral admixtures also have a great influence on the properties of lightweight foam concrete. Figure 8 shows the relationship between the amount of fly ash and the water absorption of lightweight foam concrete. The water absorption decreases at first and then increases with the fly ash content increasing, and when the fly ash content is $40 \%$, the water absorption is the lowest. The active effect of coal ash weakens the internal pore deterioration caused by the dissolution and precipitation of concrete. The secondary hydration consumes the weak $\mathrm{Ca}(\mathrm{OH})_{2}$ crystals in the concrete, reduces the internal porosity, and improves the compactness of the concrete. However, when the amount of fly ash content exceeds a certain range $(40 \%)$, too much fly ash will reduce the internal compactness of concrete, and the influence of the above effects will be greatly reduced, which leads to the increase in water absorption.

The volume water absorption of the sample is also different with different soaking times. It can be seen from Fig. 9 that the water absorption shows an upward trend with the increase of soaking time, and the water absorption of low-density samples changes more obviously with time. This may be due to a large number of pores in the low-density lightweight foam concrete, it takes a longer time to reach saturation. And because the

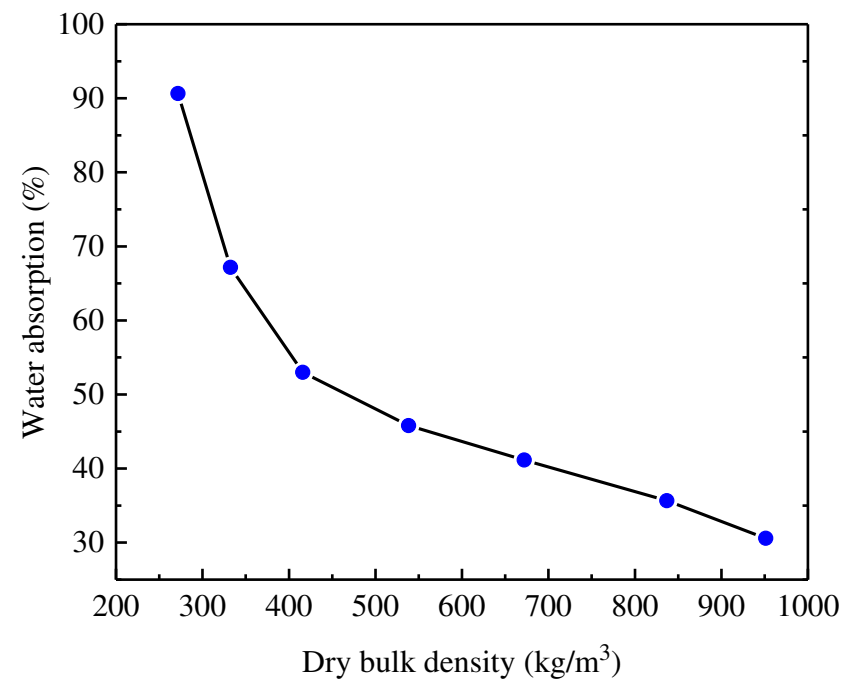

Fig. 6 Effect of dry density on water absorption 


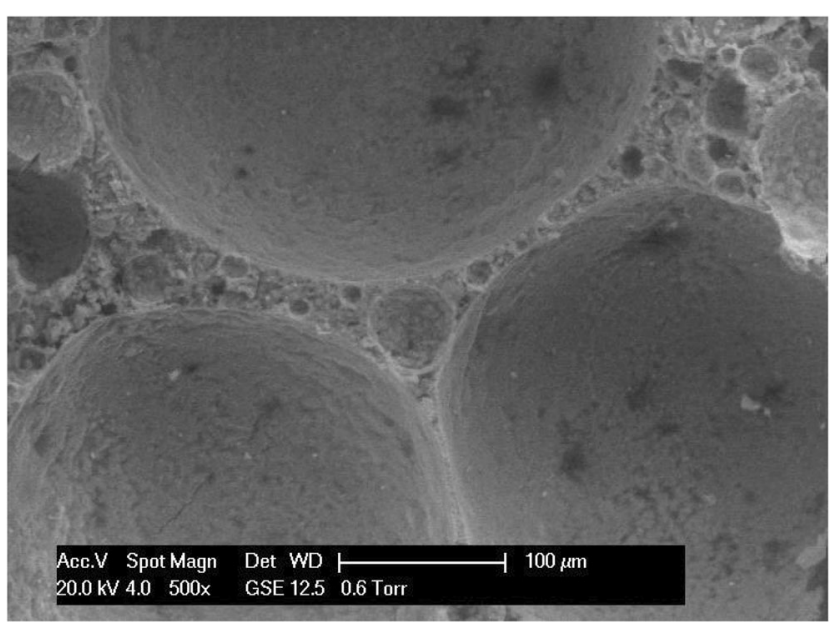

Fig. 7 SEM images with different magnifications (500×)

pores in the lightweight foam concrete are mostly closed pores, it requires a longer time for water molecules to enter the interior, which may also lead to a prolonged water absorption time.

\section{Analysis of creep characteristic}

According to the strength of lightweight foam concrete specimen, the creep loading mode was selected as follows: confining pressure and axial load. The creep test results of specimens with a density of $800 \mathrm{~kg} \cdot \mathrm{m}^{-3}$ and water content of $40 \%$, $50 \%$, and 60\% are shown in Fig. 10. The creep characteristics of lightweight foam concrete after water absorption are very obvious, and the deformation of the first stage is basically the same, which is mainly compaction, and there is no crack expansion. In the second stage, the difference is obvious with the increase of water content, and the higher the water content is,

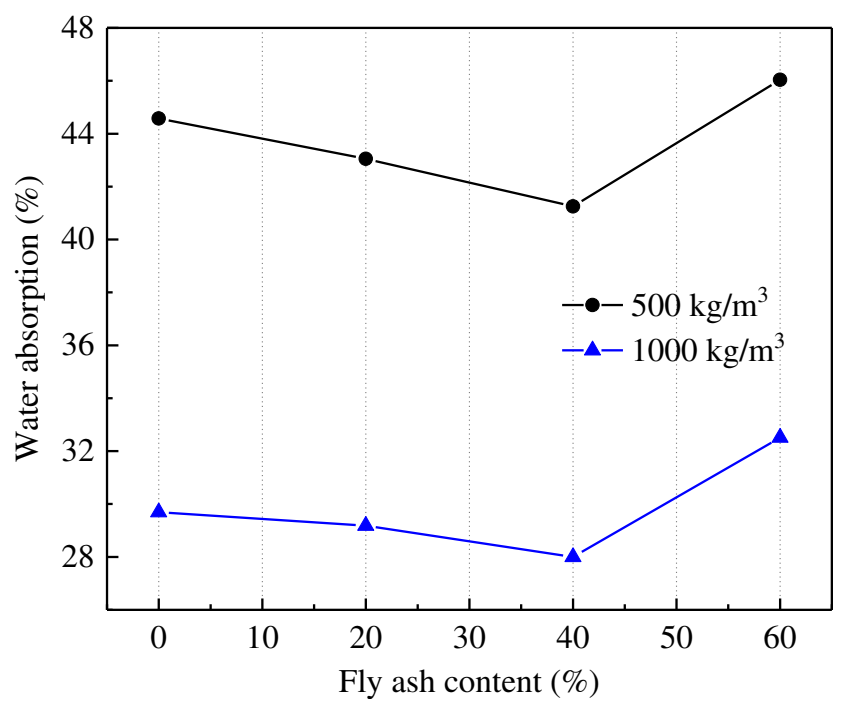

Fig. 8 Effect of fly ash content on water absorption

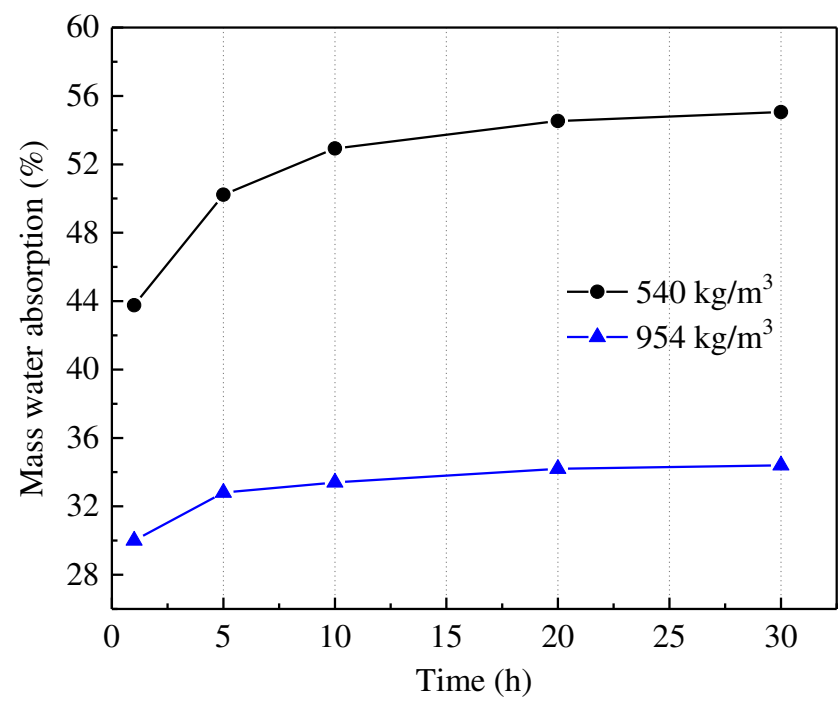

Fig. 9 Variation of water absorption with time

the greater the strain is. The third stage is the accelerated creep stage, and the cracks expand rapidly. The more the fissures develop, the stronger the weakening effect of water is. The upward trend of the creep curve increases with the increase of water content. It can be seen that with the water content increasing, the deformation and failure resistance of lightweight foam concrete degrade obviously. When the selected axial load is reduced to $100 \mathrm{kPa}$, the three-stage characteristics of creep become no longer obvious.

\section{Analysis of dry-wet cycle test}

Water has a great influence on the strength and other mechanical properties of lightweight foam concrete. In practical engineering, lightweight foam concrete may also suffer from the

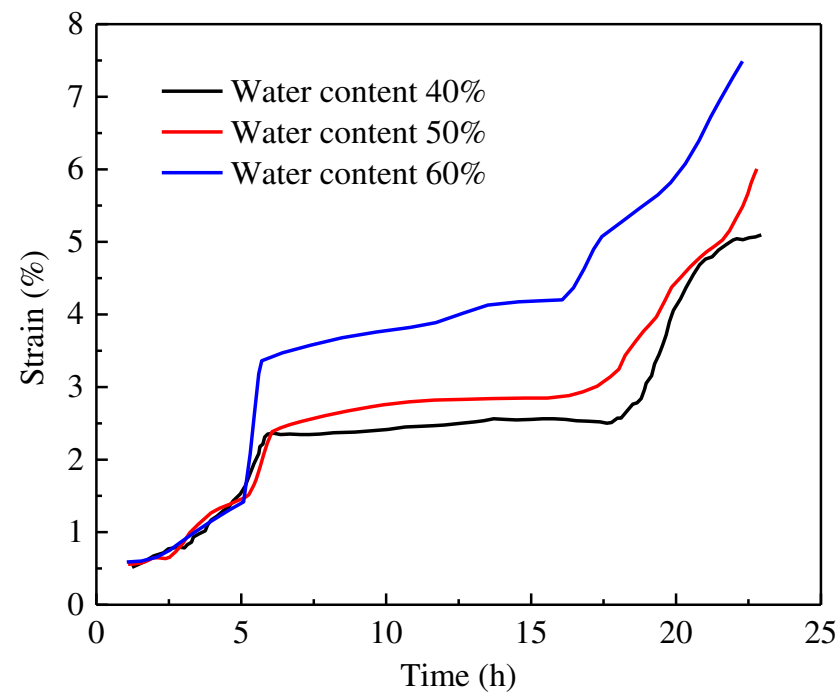

Fig. 10 Creep behavior of lightweight foam concrete with different water contents 
effects of dry-wet cycles, and this effect is stronger and more serious than the deterioration caused by the water-bearing state alone. Figure 11 illustrates the variation of internal water pressure and pore water pressure of lightweight foam concrete within 7 months of practical application. The internal water pressure and pore water pressure both change periodically in a certain range, indicating that the lightweight foam concrete suffered from dry-wet cycle erosion during this period.

The stress-strain relationship of lightweight foam concrete with an initial water content of $7 \%$ and a confining pressure of $300 \mathrm{kPa}$ under different dry-wet cycles is shown in Fig. 12. Due to the effect of the dry-wet cycle, the overall shear strength of roadbed specimens is gradually weakened. After 10 dry-wet cycles, the shear strength tends to be stable with the increase of the number of cycles. The dry-wet cycle may destroy the shear skeleton structure of the roadbed sample itself and the colloidal structure of soluble salt. With the extension of the cycle, the content of soluble salt is basically stable, and the new structure of the roadbed sample is formed. Although the shear strength is lower than that of the original, the new structure has good stability and durability.

Figure 13 represents the strength of lightweight foam concrete with different densities varying with the number of drywet cycles. It can be seen that with the number of dry-wet cycles increasing, the strength of lightweight foam concrete decreases gradually, and the two approximately satisfy the power function relationship. The lower the density is, the easier the lightweight foam concrete is to be destroyed under the dry-wet cycle. Because the strength of lightweight foam concrete is low, it is easy to soften when subjected to water erosion. And cracks occur in the drying process, which makes the water further transfer to the inside of the matrix, resulting in

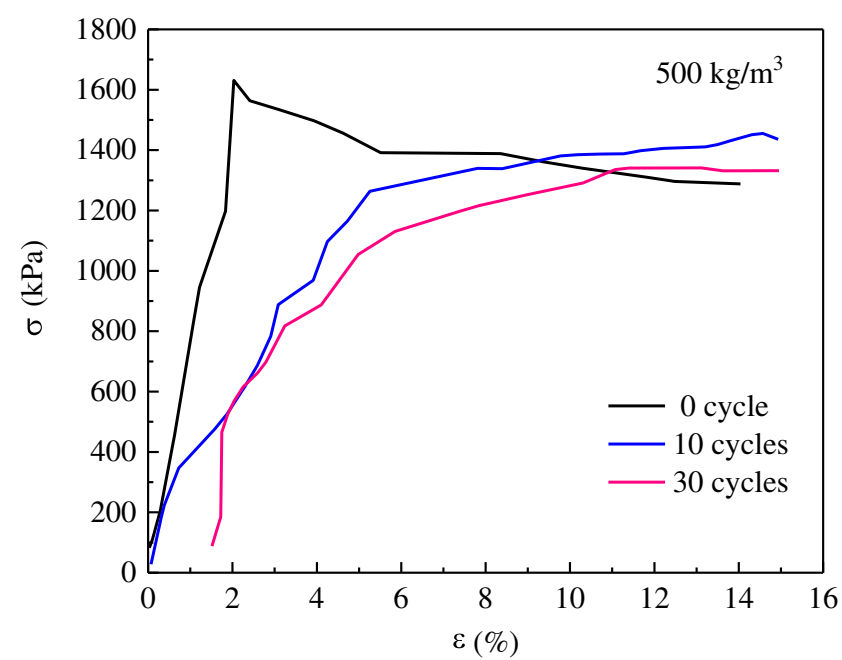

Fig. 12 Stress-strain relationship of lightweight foam concrete under dry-wet cycles

the accumulation of damage and the deterioration of lightweight foam concrete performance.

\section{Analysis of frost resistance}

Figure 14 shows the development of the dynamic elastic modulus loss of lightweight foam concrete with different dry densities with the number of freeze-thaw cycles. The frost resistance of lightweight foam concrete gradually increases with the increase of density. After 20 freeze-thaw cycles, the dynamic elastic modulus loss rate of the sample with a density of $1044 \mathrm{~kg} \cdot \mathrm{m}^{-3}$ is only $26.3 \%$, while that of the sample with a density of $279 \mathrm{~kg} \cdot \mathrm{m}^{-3}$ is $41.1 \%$, which can be considered to

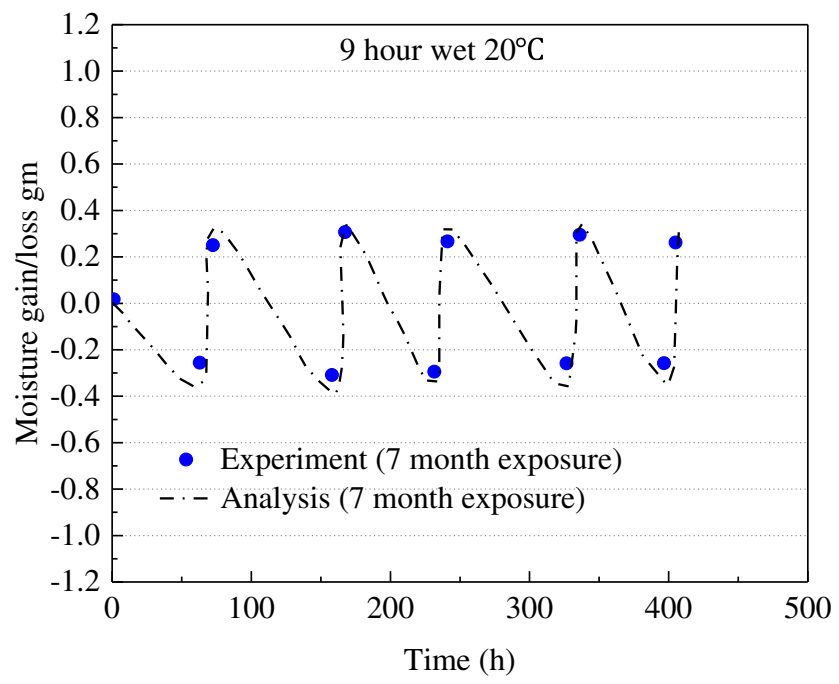

a

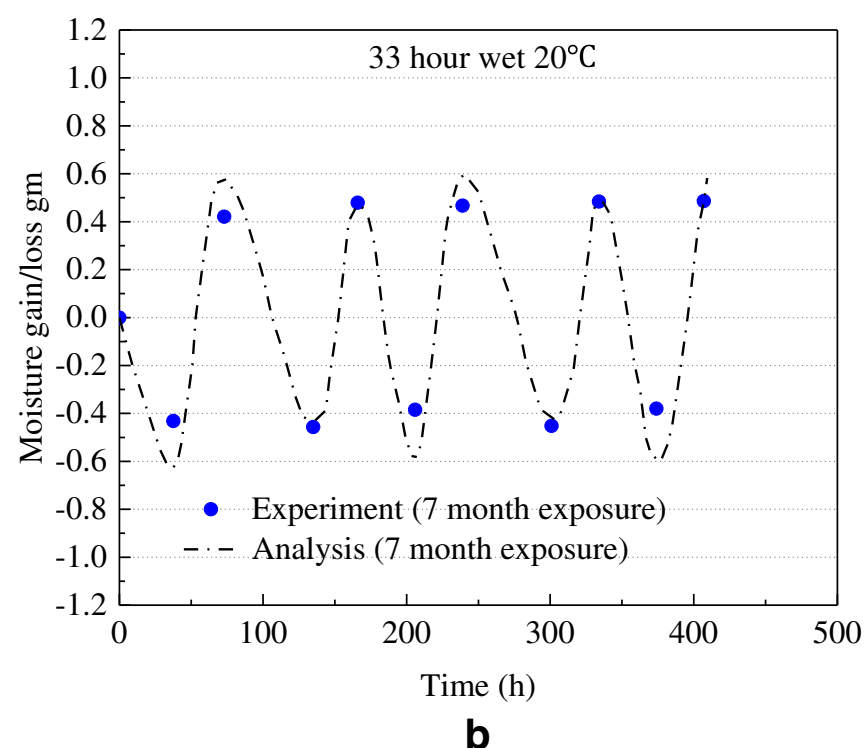

Fig. 11 Variation of hydraulic pressure and pore pressure in lightweight foam concrete. a Hydraulic pressure analysis. b Positive pore pressure analysis 


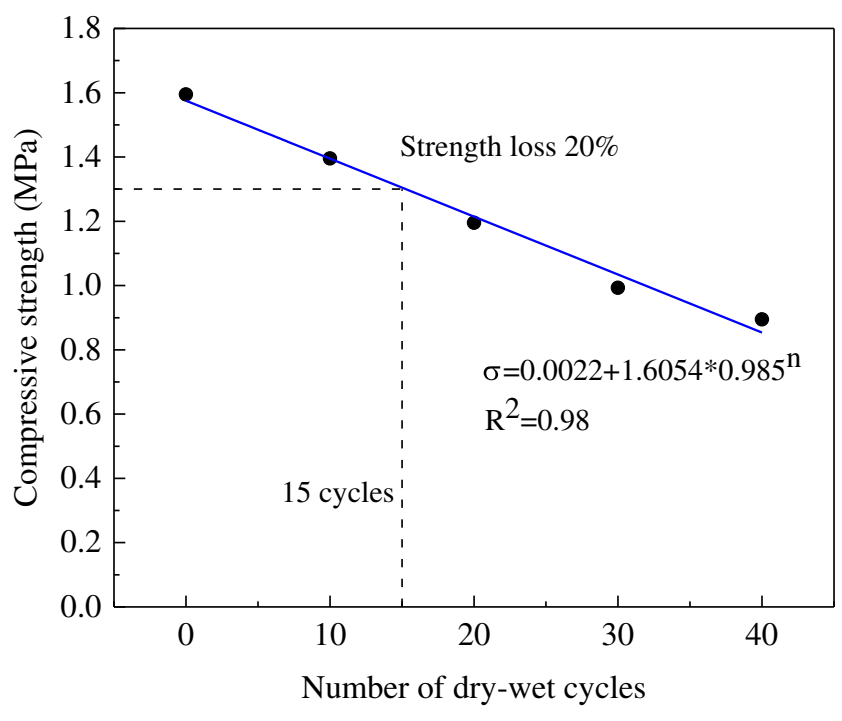

a

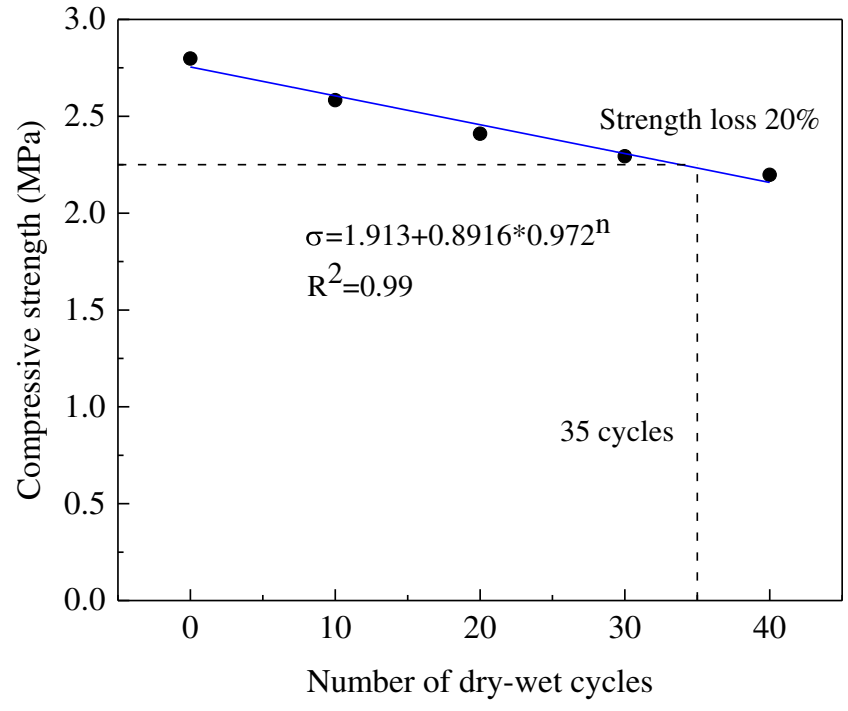

b

Fig. 13 Variations of compressive strength of lightweight foam concrete with the number of dry-wet cycles with different densities. $\mathbf{a} \rho=500 \mathrm{~kg} / \mathrm{m}^{3} . \mathbf{b} \rho$ $=800 \mathrm{~kg} / \mathrm{m}^{3}$

have reached the maximum number of freeze-thaw cycles. Due to the large proportion of internal pores and more internal through holes in low-density lightweight foam concrete, the water absorption is very large, so the frost resistance decreases.

The fly ash has an activity effect, particle shape effect, and microaggregate effect, which are helpful to reduce the internal porosity of concrete, improve the pore structure of concrete, and improve the compactness of concrete. Figure 15 illustrates the effect of fly ash content on the frost resistance of foam light concrete. When the fly ash content is $20 \%$, the frost resistance of lightweight foam concrete is equal to that of pure cement. The sample with $40 \%$ fly ash has the best frost resistance, and the loss of dynamic elastic modulus is only $27.1 \%$ after 20 freeze-thaw cycles. When the fly ash content increases to $60 \%$, the frost resistance decreases obviously, and the dynamic elastic modulus loss rate reaches $33.8 \%$ after 20 freeze-thaw cycles, which is $19.1 \%$ lower than that of pure cement. And it is close to the maximum number of freezethaw cycles. Therefore, the optimum amount of fly ash determined in this experiment is $40 \%$.

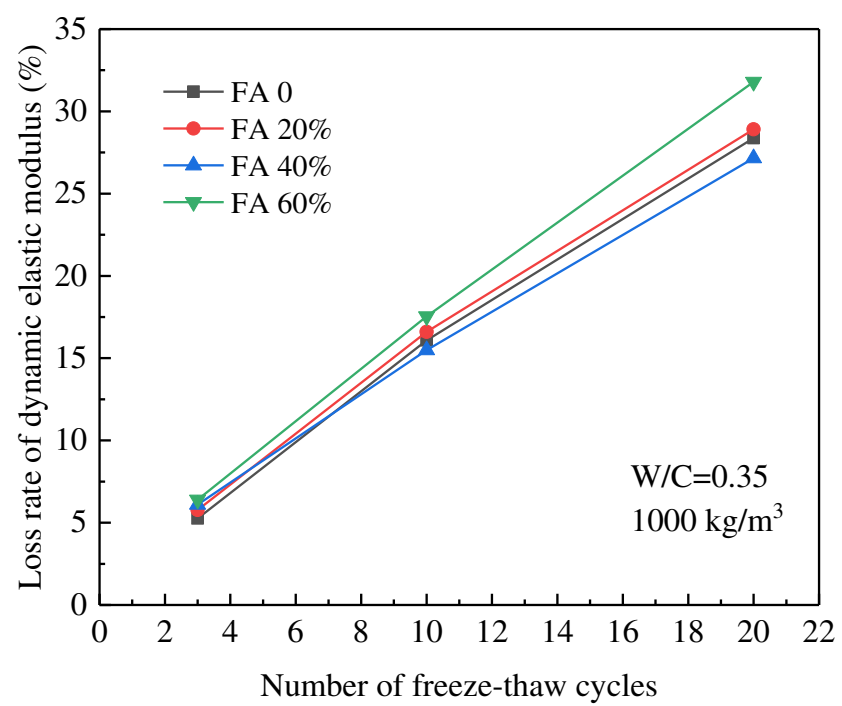

Fig. 15 Effect of fly ash content on frost resistance of lightweight foam concrete 


\section{Conclusions}

In this study, a series of cyclic triaxial tests have been carried out to investigate the dynamic behavior of lightweight foam concrete under train loading. The effects of density and fly ash content on the compression, impermeability, and frost resistance of lightweight foam concrete were analyzed. The main conclusions obtained are as follows:

(1) In the compression process of lightweight foam concrete, the stress-strain characteristics are expressed as (a) elastic deformation within the range of strength, (b) plastic deformation after exceeding the strength, and (c) ductile failure. There is still a high residual strength after failure, which is about $60 \sim 70 \%$ of its peak strength.

(2) Under cyclic load, the cumulative settlement is basically unchanged when the cyclic stress is less than the critical dynamic stress, and the cumulative deformation increases linearly until sudden failure when the cyclic stress is greater than the critical dynamic stress. The critical dynamic stress of lightweight foam concrete is generally $0.2 \sim 0.3$ times the unconfined compressive strength. The dynamic elastic modulus of lightweight foam concrete increases with the increase of density and cyclic stress amplitude.

(3) With the increase of density, the volume water absorption of lightweight foam concrete decreases gradually. The water absorption decreases at first and then increases with the fly ash content increasing, and the critical value of fly ash is $40 \%$. Water will deteriorate the lightweight foam concrete and reduce its strength.

(4) The frost resistance of lightweight foam concrete increases with the increase of density. With the increase of fly ash content, the frost resistance first increases and then decreases, and when the fly ash content is $20 \%$, the frost resistance is equivalent to that of pure cement. The optimum amount of fly ash determined in this research is $40 \%$.

\section{Declarations}

Conflict of interest The authors declare that they have no competing interests. We declare that we have no financial and personal relationships with other people or organizations that can inappropriately influence our work. There is no professional or other personal interest of any nature or kind in any product, service and/or company that could be construed as influencing the manuscript.

Open Access This article is licensed under a Creative Commons Attribution 4.0 International License, which permits use, sharing, adaptation, distribution and reproduction in any medium or format, as long as you give appropriate credit to the original author(s) and the source, provide a link to the Creative Commons licence, and indicate if changes were made. The images or other third party material in this article are included in the article's Creative Commons licence, unless indicated otherwise in a credit line to the material. If material is not included in the article's Creative Commons licence and your intended use is not permitted by statutory regulation or exceeds the permitted use, you will need to obtain permission directly from the copyright holder. To view a copy of this licence, visit http://creativecommons.org/licenses/by/4.0/.

\section{References}

Amran YHM, Farzadnia N, Ali AAA (2015) Properties and applications of foamed concrete; a review. Constr Build Mater 101:990-1005

Ashrafian A, Shokri F, Taheri Amiri MJ, Yaseen ZM, Rezaie-Balf M (2020) Compressive strength of foamed cellular lightweight concrete simulation: new development of hybrid artificial intelligence model. Constr Build Mater 230:1-14

Cong M, Chen B (2015) Properties of a foamed concrete with soil as filler. Constr Build Mater 76:61-69

Falliano D, Domenico DD, Sciarrone A, Ricciardi G, Restuccia L, Tulliani JMC, Gugliandolo E (2019) Fracture behavior of lightweight foamed concrete: the crucial role of curing conditions. Theor Appl Fract Mech 103:102297

Gopalakrishnan R, Sounthararajan VM, Mohan A and Tholkapiyan M (2020) The Strength and Durability of Fly Ash and Quarry Dust Light Weight Foam Concrete. Materials Today: Proceedings 22:1117-1124

Hengst RR, Tressler RE (1983) Fracture of foamed portland cements. Cem Concr Res 13(1):127-134

Hilal AA, Thom NH, Dawson AR (2015) On void structure and strength of foamed concrete made without/with additives. Constr Build Mater 85:157-164

Hu C, Li H, Liu ZW, Wang Q (2016) Research on properties of foamed concrete reinforced with small sized glazed hollow beads. Adv Mater Sci Eng 2016:1-8

Jerman M, Keppert M, Výborný J, Černý R (2013) Hygric, thermal and durability properties of autoclaved aerated concrete. Constr Build Mater 41:352-359

Jones MR, McCarthy A (2005) Preliminary views on the potential of foamed concrete as a structural material. Mag Concr Res 57(1):21-31

Kearsley EP, Wainwright PJ (2001) The effect of high fly ash content on the compressive strength of foam concrete. Cem Concr Res 31(1):105-112

Kearsley EP, Wainwright PJ (2002) The effect of porosity on the strength of foam concrete. Cem Concr Res 32(2):233-239

Kuzielov E, Pach L, Palou M (2016) Effect of activated foaming agent on the foam concrete properties. Constr Build Mater 125:998-1004

Liu ZW, Zhao K, Hu C, Tang YF (2016) Effect of water-cement ratio on pore structure and strength of foam concrete. Adv Mater Sci Eng 2016:1-9

Otain J, Toshifumi M, Yoshiaki K (2002) Visualization for engineering property of in-situ light weight soils with air foams. Soils Found 42(3):93-105

Ramamurthy K, Nambiar EKK, Ranjani GIS (2009) Classification of studies on properties of foam concrete. Cem Concr Compos 31(6):388-396

Satoh T, Tsuchida T, Mitsukuri K, Hong Z (2001) Field placing test of lightweight treated soil under seawater in Kumamoto Port. Soils Found 41(5): 145-154

Tan X, Chen W, Tian H, Yuan J (2013) Degradation characteristics of foamed concrete with lightweight aggregate and polypropylene fibre under freeze-thaw cycles. Mag Concr Res 65(12):720-730

Toshiyasu T, Nobuo M, Hisashi T (2000) Studies on quality control of foamed mixture lightweight soil. Doboku Gakkai Ronbunshuu 658:141-152

Wang R, Gao P, Tian M, Dai Y (2019) Experimental study on mechanical and waterproof performance of lightweight foamed concrete mixed with crumb rubber. Constr Build Mater 209:655-664 